\title{
Morphological aspects of Bismuth ferrite powders prepared by microwave-assisted hydirothermal method
}

\author{
V.-A. Surdu ${ }^{1}$, Y. Wang ${ }^{2}$, A.C. Bîrcă ${ }^{1}$, E. Tanasă ${ }^{1}$, E. Andronescu ${ }^{1}$ \\ 1 Faculty of Applied Chemistry and Materials Science, University Politehnica of Bucharest, Romania \\ 2 ENSIL-ENSCI Limoges, France \\ * Correspondence: adrian_v_surdu@yahoo.com; Scopus ID: 56941744700
}

$\mathrm{BiFeO}_{3}$ particles were synthetized by a fast, reproducible and environmental friendly microwave-assisted hydrothermal method. The aim of the study was the investigation of increased pressure and mineralizer concentration on the reaction mechanism, morphology of particles and aggregates as well as magnetic behavior. Powders were studied when using $\mathrm{KOH}$ mineralizer concentration from 4 to $12 \mathrm{M}$ at room temperature and under microwave-hydrothermal conditions at 40 bar and 150 or $200^{\circ} \mathrm{C}$.

The reaction mechanism depends on the temperature of the microwave-hydrothermal treatment and the concentration of $\mathrm{KOH}$ mineralizer. The precursor powder obtained after coprecipitation step consists of $\mathrm{Bi}_{2} \mathrm{O}_{3}, \mathrm{Fe}_{2} \mathrm{O}_{3}$ and $\mathrm{Bi}_{25} \mathrm{FeO}_{40}$ in different ratios. After the treatment at $40 \mathrm{bar}$ and $150^{\circ} \mathrm{C}$ for $1 \mathrm{~h}$ the reaction between precursors is not complete, therefore resulting secondary phases of $\mathrm{Bi}_{25} \mathrm{FeO}_{40}$ and $\mathrm{Fe}_{2} \mathrm{O}_{3}$. $\mathrm{BiFeO}_{3}$ particles were successfully synthesized at $40 \mathrm{bar}$ under microwave-hydrothermal conditions at a temperature of $200^{\circ} \mathrm{C}$ and a concentration of $\mathrm{KOH}$ of at least $8 \mathrm{M}$. At $6 \mathrm{M}$, the composition consisted of $98.5 \% \mathrm{BiFeO}_{3}$ and $1.5 \% \mathrm{Bi}_{2} \mathrm{O}_{3}$ as evidenced by Rietveld refinement.

The competition between dissolution and precipitation of $\mathrm{Bi}^{3+}$ and $\mathrm{Fe}^{3+}$ in $\mathrm{KOH}$ solutions of different concentrations was investigated by Raman spectroscopy and EDS analysis. Thus, at $200^{\circ} \mathrm{C}$ there was evidenced a $\mathrm{Bi}_{2} \mathrm{O}_{3}$ secondary phase for $6 \mathrm{M} \mathrm{KOH}$ concentration and poor control of $\mathrm{Bi} / \mathrm{Fe}$ ratio in $\mathrm{BiFeO}_{3}$ at $\mathrm{KOH}$ concentrations of 10 and $12 \mathrm{M}$.

Particle and aggregates morphology depicted by FE-SEM investigations showed a tendency to form irregular shaped particles at $\mathrm{KOH}$ concentration of $6 \mathrm{M}$, for which the reaction is not complete. When increasing the concentration, $\mathrm{BiFeO}_{3}$ particles exhibit regular shapes from cubic at $8 \mathrm{M}$ to cvasi-spherical at $14 \mathrm{M}$.

$\mathrm{M}-\mathrm{H}$ curves characteristics illustrate that $\mathrm{Bi} / \mathrm{Fe}$ ratio and preferential orientation of crystal growth influence the magnetic behavior of $\mathrm{BiFeO}_{3}$ crystalline powders.

Keywords: Bismuth ferrite powder, microwave, hydrothermal method. 
Bismuth ferrite powders prepared by microwave-assisted hydrothermal method

\section{Funding}

Not applicable.

\section{Acknowledgments}

Not applicable.

\section{Conflicts of Interest}

The authors declare no conflict of interest.
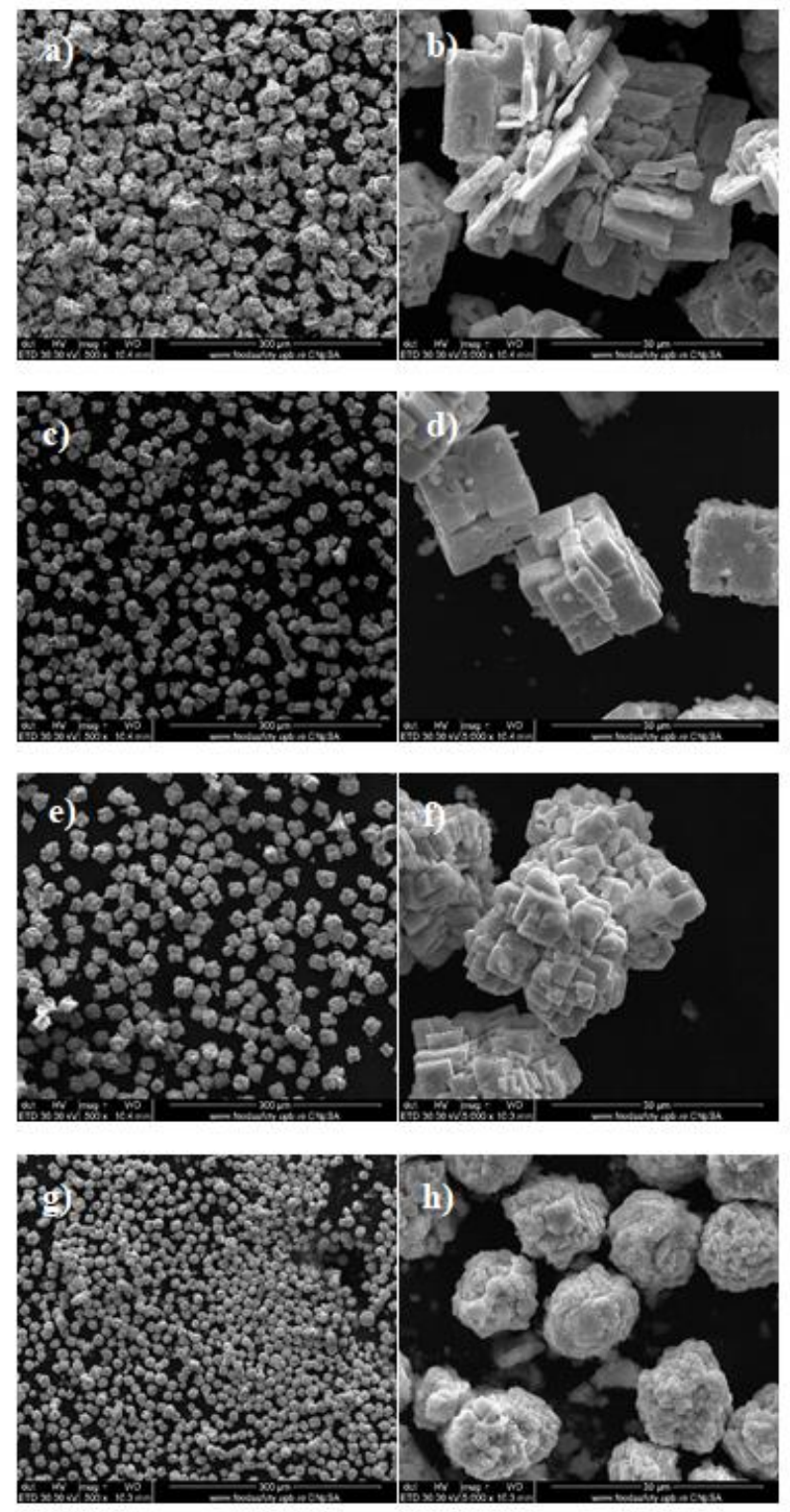

Figure 1. a), c), f), h) FE-SEM general view, b), d), g), i) FE-SEM detail at 8, 10, 12 and $14 \mathrm{M} \mathrm{KOH}$ concentration of $\mathrm{BiFeO}_{3}$ powders.

(C) 2019 by the authors. This article is an open access article distributed under the terms and conditions of the Creative Commons Attribution (CC BY) license (http://creativecommons.org/licenses/by/4.0/). 